\title{
A TRANSDISCIPLINARY PERSPECTIVE ON GENDER MAINSTREAMING IN INTERNATIONAL DEVELOPMENT: THE CASE OF THE CGIAR
}

Diana E. Lopez and David Ludwig

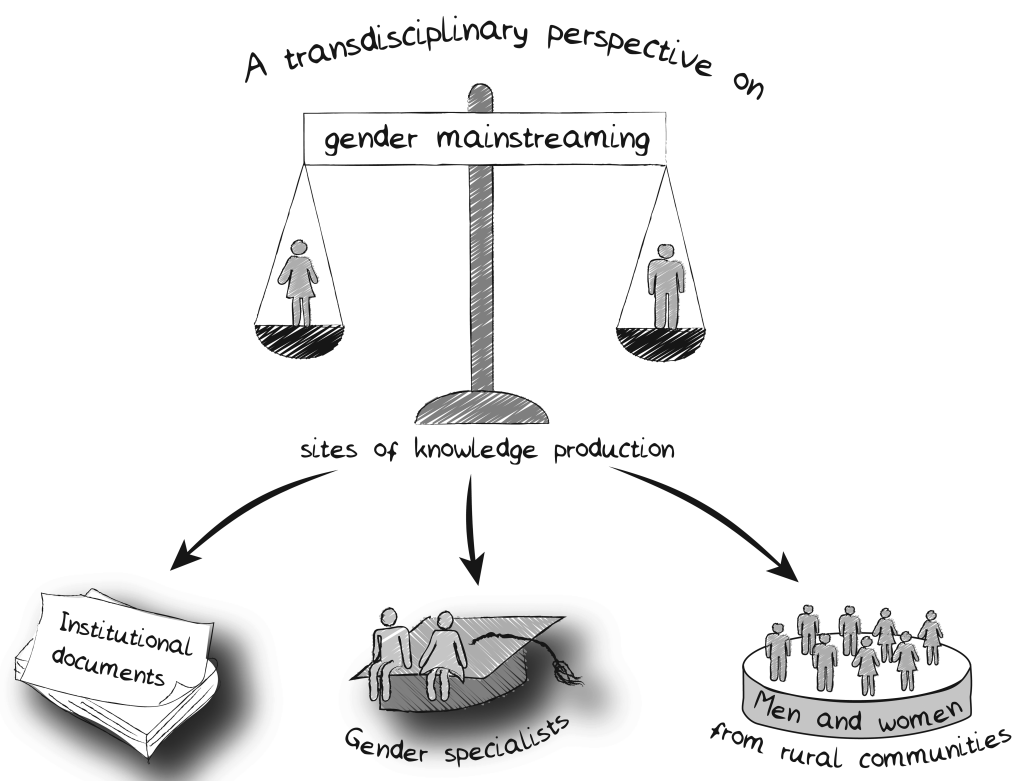

\section{Introduction}

Gender mainstreaming constitutes the dominant policy approach to gender in international development (Beck, 2017; Lyons et al., 2004; Verma, 2014). First promoted at the 1995 World Conference on Women in Beijing, the strategy seeks to integrate women's and men's concerns and experiences across all aspects 
of development programmes - from conceptualisation to evaluation (Tegbaru et al., 2010). Endorsed by donors and high-level decision makers, it has become integrated across development programmes. However, its efficacy to achieve gender equality is widely questioned (Charlesworth, 2005; Palmary \& Nunez, 2009). Feminist scholars are especially critical of the way gender has been mainstreamed across organisations. For them, mainstreaming has led to a depoliticisation of gender - a concept that is essentially political (Baden \& Goetz, 1998; Hawthorne, 2004).

At the heart of the critique lies the perception that gender issues in development organisations are often sidelined or implemented in a truncated form (Palmary \& Nunez 2009; Sohal, 2005); for example, by prioritising short-term targeted measures to the detriment of long-term gender-transformative goals; by an organisational preference for universalism which fails to account for context-specific gendered experiences and practices; and by reducing gender complexities into ready-to-apply packages such as gender tools, frameworks, and guidelines. Gender mainstreaming has also been labelled as 'neo-colonial' due to its projection of a contingent perspective of gender onto the developing world without acknowledging its (European, liberal, middle-class, technocratic, white, feminist) origins (Lyons et al., 2004; Østebø, 2015). These issues of conceptualisation and institutionalisation have led many feminist and gender professionals to question the gender mainstreaming project as a whole (Cornwall et al., 2007; Lyons et al., 2004; Razavi \& Miller, 1995; Sohal, 2005).

The challenges of gender mainstreaming in international development therefore benefit from a transdisciplinary perspective that highlights opportunities for mutual learning about gender by incorporating different sites of knowledge production. Building on insights from feminist epistemology (Anderson, 2000; Longino, 2017), this chapter develops an account of 'situated knowledge' (Haraway, 1988) that recognises diverse epistemic resources for engaging with gender in international development. Rather than interpreting gender mainstreaming through a decontextualised academic perspective, this chapter highlights different forms of situated knowledge about gender and their embedding in different sites of knowledge production. Harding's (2015) notion of 'strong objectivity' emphasises that this acknowledgement of the situated character of knowledge does not imply a cultural relativism that treats all beliefs about gender as equally valid. On the contrary, the situatedness of knowledge can strengthen objectivity by diversifying its evidence base through the inclusion of actors who often remain marginalised in international development projects. Rather than 'romanticizing and/or appropriating the vision of the less powerful while claiming to see from their positions' (Haraway, 1988, pp. 583-584), using a lens of situated knowledge enables a critically reflexive engagement with diverse epistemic resources. Situated knowledge further allows for a transdisciplinary perspective that engages with standpoints that commonly remain marginalised in dominant framings of gender mainstreaming.

This chapter examines situated knowledge about the contested notion of gender equality in the context of a major agricultural organisation, the CGIAR 
(Consultative Group for International Agricultural Research), by investigating how this notion is portrayed in three sites of knowledge production. A closer examination at this organisation is pertinent given its impact in agricultural research as well as its political influence in the agricultural research and development agendas of the countries where it works. Our triangulated approach builds on (1) a literature analysis of seven CGIAR institutional documents; (2) semi-structured interviews conducted with 25 gender specialists across the CGIAR; and (3) focus group discussions about gender equality with women and men from 13 countries who participated in GENNOVATE-a CGIAR initiative focused on the interlinkages between gender norms, agency, and innovation in agriculture (Table 3.1). Informed by feminist and innovation theories, GENNOVATE features a comparative, qualitative, case study method and purposive sampling techniques to detect broad gender normative patterns while retaining their grounding in local contexts and realities (see Badstue et al., 2018). The triangulated approach guides our general proposal towards a transdisciplinary perspective for gender mainstreaming in the CGIAR and similar organisations.

Transdisciplinarity has been endorsed in development as a methodology that brings diverse forms of knowledge together. However, as discussed in Chapter 1, transdisciplinary knowledge integration is a challenging process in light of heterogenous ontologies and values that underlie situated knowledge. In the development sector, knowledge about 'gender' constitutes a prime example of these difficulties, as local perspectives frequently diverge from those of development organisations - often leading to the marginalisation of local perspectives on 'gender.' Yet, and as evidenced in Chapter 16 in this volume, significant opportunities arise from challenging the epistemic hierarchy (Table 3.1).

\section{Three sites of knowledge production about 'gender equality' According to CGIAR institutional documents}

The CGIAR is an international non-profit organisation in agricultural research for development. It has the world's largest global agricultural innovation network, including national governments, academic institutions, global policy bodies, private companies, and non-governmental organisations (Özgediz, 2012). The CGIAR is constituted by 15 autonomous research centres ${ }^{1}$ working in agricultural policy, commodity crops and livestock, eco-regional, and natural resource management. Originally established in 1971 with a focus on technological efficiency and productivity for agricultural transformation, the CGIAR has expanded its emphasis beyond efficiency and productivity to include other goals, from sustainability to gender equality. At present, the organisation is undergoing the 'One CGIAR' reform aimed at further unification among centres, including an improvement of the current gender mainstreaming strategy 


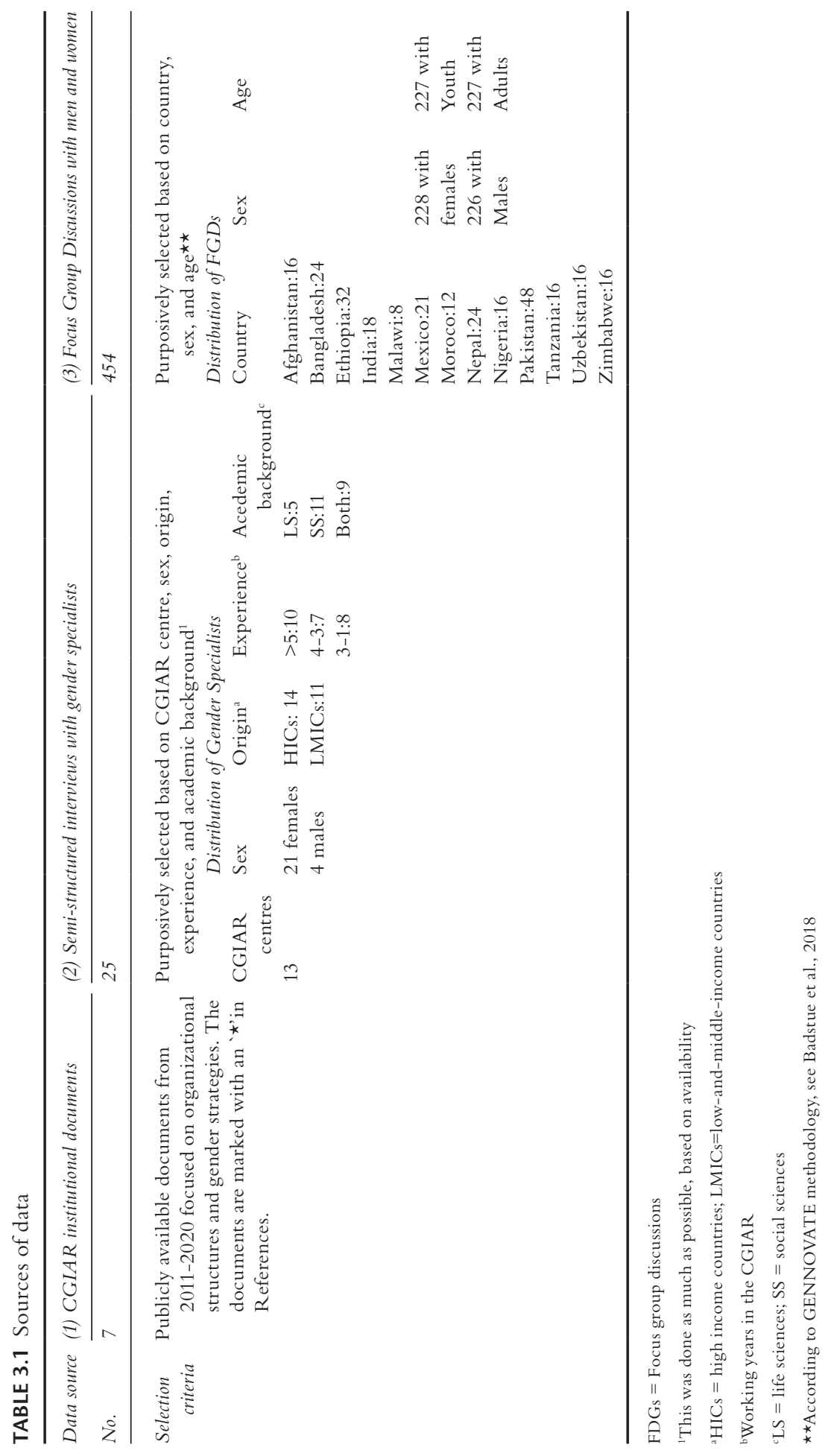


(CGIAR, 2019). For the first time in its history, the strategy identifies gender equality as one of the five impact areas to be addressed by the reform (CGIAR, 2019).

Across the documents analysed, gender equity/equality are consistently presented as crucial for achieving development goals such as poverty reduction, improved food and nutrition security, and better natural resource systems and ecosystem services (CGIAR-IEA, 2017; CGIAR, 2016, 2019); as well as 'prerequisite for growth, prosperity and competitiveness' (CGIAR, 2020a, p. 1). The current consortium-level gender strategy further reflects this orientation by committing research programmes to developing agricultural technologies, farming systems, and policies to support women's agricultural productivity across the 70 countries where the CGIAR works (CGIAR, 2011). This is operationalised by including clearly assigned budgets, integration plans, and monitoring and evaluation mechanisms as part of the CGIAR gender mainstreaming strategy (CGIAR, 2011). Besides an emphasis in supporting rural women's agricultural productivity, the recent Action Plan for Gender, Diversity, and Inclusion in CGIAR's Workplaces (CGIAR, 2020b) indicates that gender equality is becoming a central component within the organisation. This is evidenced, for instance, by the CGIAR's commitment to increase women's representation across the organisational hierarchy by 35\% (CGIAR, 2020b). Fostering gender equality within the organisation in this and other ways is thus expected to lead to 'significant improvements in employee engagement, ability to innovate, responsiveness to changing client needs and team collaboration [...] [which] allows to draw on different perspectives to enhance the quality of our decision making, deepen the relevance of our advice and outputs, and enhance our efficiency and effectiveness' (CGIAR, 2020a, p. 1). The documents assert that the risk of failing to attain a diverse and inclusive environment will result in the CGIAR losing its position as a front runner in agri-food systems research for development (CGIAR, 2020a).

The analysis suggests that institutional knowledge about gender is primarily produced in its relation to broader CGIAR objectives. Both in the workplace and in relation to the research and strategies developed to serve rural women, the CGIAR increasingly produces knowledge about gender but positions gender equality less as a goal in itself and more as an instrument for wider institutional goals - i.e., strengthening its strategic position as a development organisation or contributing to goals such as food security and poverty reduction.

\section{According to gender specialists working in the CGIAR}

We conducted interviews with CGIAR gender specialists from 2018 to 2020 focused on four areas: (i) institutional climate for gender work in the organisation; (ii) differences and similarities in gender research across the CGIAR; (ii) experiential learning in translating gender theory into practice; and (iv) institutional 
challenges and opportunities to create gender-transformative change. In this section, we examine their views about gender equality.

Overall, the interviews indicate broad agreement among gender specialists about gender equality being part of the mandate of the CGIAR (21 out of 25) and about their own work contributing to this mandate (24/25). With most of them also thinking that 'doing gender' means focusing on both women and men (22/25). Despite this common starting point, gender specialists highlighted different concerns and roles in their contributions to gender equality - evidencing the contested nature of this issue within the CGIAR. For example, the interviews indicate different attitudes towards gender-sensitive approaches (that aim to address gender-specific needs) and gendertransformative approaches (that aim to change gender-specific roles). Fourteen gender specialists, mostly from high-income countries, stated that the organisation needs to move from being gender-sensitive to become gender-transformative as noted by a specialist from CIMMYT,

I firmly believe that transformative research is the only way to get closer to gender equality in the agricultural sector. But I do not believe the CGIAR has the expertise currently to do that well. Therefore, they could potentially be doing harm if they took on that particular mandate. We don't have the methods, we don't have the skills [...] So, if we suddenly move to transformative methods, they're going to mess it up and they're going to do harm.

A researcher from IWMI also emphasised that a lack of transformation perpetuates inequality and poverty:

We [gender specialists] have inspired a whole generation of women to become researchers and scientists; that's a win, right? But we have not transformed the lives of rural women in different parts of the world [...] I think part of the development work [we do] also perpetuates poverty, because if you keep thinking of them as women who lack agency then they'll forever be poor women who lack it. If they had any [agency] we will be out of a job, so in a way is good for us [development workers] that there is inequality.

However, 11 specialists, mostly from low-and-middle-income countries (LMICs), considered that being gender-sensitive suffices in some research areas such as breeding, and that transformative ambitions do not always benefit the rural communities that are served by the CGIAR work:

I don't think we have to transform everything. We need to find the things that work well in the communities without necessarily transforming their culture [...] so I think it's both approaches, but I mean, these white people in those senior positions, oh, they are all about 'we have to transform and to use transformative approaches.' I say that if you go to the communities and talk about 
transforming structures and forget to see what is good and works there you just confuse the community members. So no, I don't think it should be fully transformative but I think we have to be strategic and know which approach to use in different cases [...] Honestly, I don't think even gender people [in the CGIAR] really understand what it is that we want to transform for sure and I worry that if we try to push something that we don't know, it would just backfire. So, is transformation the best way for the CGIAR to go? That's exactly what we should be asking ourselves now. (Specialist from ILRI)

These heterogeneous attitudes towards gender-transformative and gendersensitive approaches indicate the diversity of gender specialists' perspectives across the CGIAR. On the one hand, transformative ambitions towards gender reflect that gender specialists are situated in feminist discourses that highlight systemic issues of inequality and the limitations of incremental approaches for achieving gender equality. On the other hand, endorsement of gendersensitive perspectives reflects that gender specialists in the CGIAR often see themselves as working together with local communities in improving gender equality and people's livelihoods without necessarily striving to transform local structures.

The interviews also revealed that gender specialists do not always consider their position aligned with the institutional gender perspective of the CGIAR. For example, specialists widely agreed that they are expected to contribute, among other goals, to (a) build institutional gender awareness (25); (b) empower rural women and help them challenge unequal power structures (18); (c) empower other women researchers and staff in their centre (25); and (d) help to increase the rate of adoption of practices and/or technologies developed by their centre (22). However, 20 respondents felt that (d) was more an institutional priority than their own. Furthermore, 22 specialists noted that while (a)-(c) were only deemed as 'desirable' objectives by the organisation, they themselves considered these goals as being fundamental to their jobs.

The interviews suggest different forms of situated knowledge about gender equality influencing gender specialists' engagements with gender and agricultural innovation issues. The heterogeneous responses regarding gender-transformative and gender-sensitive approaches, for instance, reflect how specialists produce knowledge about gender equality in heterogeneous contexts and through varied standpoints that contribute to different attitudes towards development interventions. Furthermore, the situated knowledge of gender specialists partially differs from the institutional knowledge of the CGIAR, which focuses on the relation between gender equality and wider institutional goals.

\section{According to men and women from rural communities}

This section draws from two questions about gender equality asked during GENNOVATE focus group discussions (FGDs) with men and women from rural 
communities across 13 countries. The first question aimed to gather descriptive responses to the term 'gender equality'; whereas the second sought to encourage people to share their own views-including making individual assessments.

Almost all FGDs (445/454) had come across the concept of gender equality; with most responses to the first question (what comes to mind when you think of the term gender equality?) closely related to mainstream definitions of gender equality; including references to equal rights, responsibilities, and opportunities between women/girls and men/boys. People also spoke about gender equality in relation to several issues. As shown in Figure 3.1, gender equality was most frequently discussed in reference to cultural, social, and gender norms (i.e., informal institutions). For instance, seclusion norms were reported to affect women's freedom of mobility, especially in Afghanistan, Bangladesh, India, and Pakistan. Gender equality was also identified to provoke strong emotional responses-particularly stress, discomfort, and even violence.

In response to the second question (do you think gender equality is a good or a bad thing?), most people talked about gender equality favourably. Overall, women made more favourable assessments than men $(63 \%$ compared to $52 \%)$; with young women and men making the most favourable assessments (Figure 3.2).

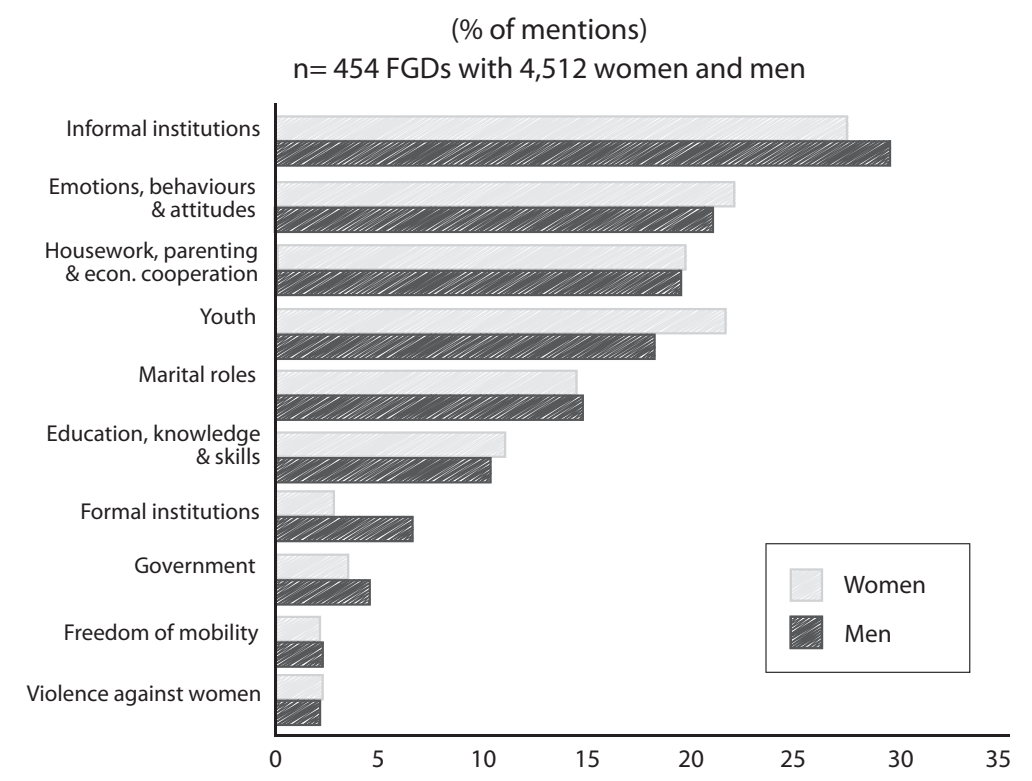

FIGURE 3.1 Topics most frequently discussed by women and men in relation to 'gender equality.' 


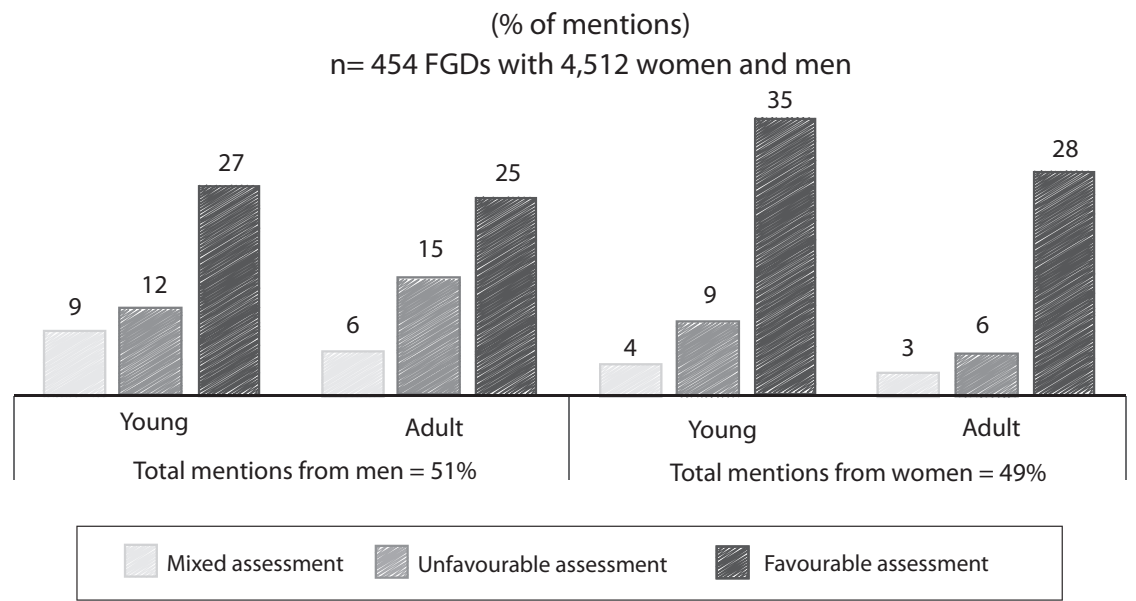

FIGURE 3.2 Normative assessments of 'gender equality' among men and women from different age groups.

However, the understanding of and knowledge about gender equality between different groups of men and women was diverse. People referenced various sources of knowledge influencing their own assessment of gender equality. These sources derived from (1) their own (bodily) experience, i.e., setting themselves as examples or by referencing other cases they had seen or heard about; (2) external conceptualisations, such as attending a training about gender equality; and (3) associations between external conceptualisations of gender equality with local notions of equality between men and women as described by religion, the Holy Scriptures, Sharia law, or cultural norms and traditions. The following quotes show how attitudes towards gender equality interact with situated knowledge about cultural, economic, and religious contexts:

\section{Ethiopian FGDs}

We know about equality and today there are meetings to ensure women's participation. But when we go out and attend the meeting, we face problems back home and our husbands asked where we have been and would say 'go back where you have been, go ahead leave the house.' Then he will beat us when we refuse to leave the house. There are women who are not even allowed to go anywhere so they cannot participate in trainings or meetings. (Ethiopian adult woman)

I know a man who sent his wife to an Arab country to work. He prepared meals including baking 'Injera' and feeding his children all the time while she was absent. Since this was not an accustomed practice in our 
community we were amused by his ingenuity. This is what I call equality because we all learned from him. (Ethiopian adult man)

\section{Afghan FGDs}

Equality between men and women is good. Islam has shown us the rights of men and women. In Islam they are not as equal as stipulated by the human rights advocates and from what people from NGOs are talking nowadays. But their rights are clearly mentioned in the Quran. (Adult man from Afghanistan)

We men are responsible of all the rights that Allah has given to women. For instance, if we make dresses for ourselves but not for our wives, this is wrong. We, in accordance to the regulations of Sharia, have to meet the needs of women. A family is also responsible to provide equal education rights to their kids, both girls and boys. I would say as an example, that of two families deciding that when their kids grow-up they will marry. When the kids grow-up, if the girl doesn't like to marry the boy, the Quran has given right to the girl to decide whom to marry. So, if she is illiterate, she will not know her rights. It is then compulsory to provide education to kids in order for them to have enough knowledge. (Adult man from Afghanistan)

\section{Zimbabwean FGDs}

Gender equality is good only when it applies to the work place. In the past it was rare to see a woman driving a car or being a technician. Now women drive cars and have technical jobs. We [men] have no problem with that, but let it end there. If we apply gender equality in the home, we lose our cultural values and practices. (Adult man from Zimbabwe)

Gender equality is a bad thing because we [men] are not receiving the respect we are supposed to get from our wives. As I was passing by a certain household, I heard a woman saying to her husband, 'Can you wash these plates, please.' You hear a woman saying can you please wash these plates not acknowledging that I would have paid 15 head of cattle to her parents for her to be with me. Otherwise, this gender equality [issue] is one of the causes of poor rains because long ago we used to have enough rainfall, but when this gender equality was introduced our climate suddenly changed. (Adult man from Zimbabwe)

Figure 3.1 shows that people across geographical settings associate gender equality with particular sociocultural norms and gender stereotypes (e.g. around economic participation or education); the quotes showed how people's attitudes are also embedded in different forms of situated knowledge: for example, patriarchal practices of social control (Ethiopia, quote 1), changing gender roles due to migration (Ethiopia, quote 2), local religious interpretations of gender relations (Afghanistan, quote 1+2), or sociocultural conflicts arising from changing gender 
roles (Zimbabwe, quote 1+2). As gender permeates all dimensions of social life, everybody can be seen to have their own particular 'gender knowledge' with their 'durable gendered assumptions [...] enmeshed in local understandings of "mainstream” issues and local practices' (Cavaghan, 2017, p. 43). However, much of the situated knowledge about the contextual negotiations of gender equality is not available to external gender specialists or even present at the CGIAR's institutional level. This section highlights the opportunities of incorporating diverse forms of situated knowledge within the gender and agriculture initiatives in the CGIAR.

\section{Reflections and conclusions}

Gender mainstreaming has become increasingly challenged as an institutional strategy that often pursues short-term and technocratic goals that lack transformative capacities towards gender equality (Charlesworth, 2005; Palmary \& Nunez, 2009; Verma, 2014). In the international development context, gender mainstreaming has also been criticised as relying on a narrow Western understanding of gender that is projected onto LMICs (Østebø, 2015). This chapter aims to contribute to a transdisciplinary reconfiguration of gender mainstreaming in the CGIAR and in similar organisations by expanding its treatment of gender equality into one that acknowledges its contested and context-specific nature.

As advanced here, diverse knowledge about gender equality is associated with distinct sites of knowledge production. At the institutional level, CGIAR knowledge about gender equality/equity primarily relates to its role in achieving development goals from reduced poverty to food security to sustainability. Gender specialists, however, express knowledge about gender equality in relation to systemic issues that demand transformative change, as well as about gender sensitivity, being crucial for achieving gender equality in local community structures. Whereas the focus group discussions denote knowledge about gender equality in relation to personal bodily experiences, external conceptualisations, and local cultural and religious norms and socio-economic realities. This heterogeneity of situated knowledges about gender equality points towards the need for a transdisciplinary perspective. Especially, as a neglect of such knowledge diversity runs the risk of reproducing a narrow perspective on gender equality that largely reflects the concerns and issue framing of dominant institutional actors. However, transdisciplinary processes that bring different sites of knowledge production together do not only come with opportunities but also with many challenges (Ludwig \& El-Hani, 2020). In the three sites of knowledge production researched, many challenges for transdisciplinary knowledge integration are salient as gender equality becomes interpreted through very different (and sometimes outright contradictory) concerns, values, and worldviews.

Despite challenges in knowledge integration, engagement with different sites of knowledge production-in this case, in relation to the contested notion of 
gender equality — creates substantial opportunities for mutual learning. We conclude with three areas of potential contributions for adopting a transdisciplinary perspective on situated knowledges in current debates about the formulation of a CGIAR gender mainstreaming strategy.

(a) From decontextualisation to context-specific knowledge through strategic gender research: A new CGIAR strategy for gender mainstreaming could become more inclusive towards different forms of situated knowledge by strengthening 'strategic' gender research, ${ }^{2}$ in which projects are specifically designed to engage with situated knowledge about gender and food security. For instance, the knowledge derived from rural men and women in this chapter was only possible through the support of strategic gender initiatives like GENNOVATE-which highlights the need for CGIAR research and technologies to be designed and adapted in accordance with the situated knowledge of the actors affected by CGIAR interventions. Increasing representation of local knowledge through strategic gender research would also facilitate a shift from research that identifies gender inequalities to one that seeks to address them in practice. As highlighted in the wider literature on local knowledge (Lacey, 2019), academic texts tend to produce decontextualised knowledge (e.g. general statements about the link between gender equality and food security in institutional documents) while the knowledge of rural communities tends to be more adapted to its local context (e.g. statement about how gender equality relates to social particularities in a village). This context sensitivity of local knowledge often proves indispensable for moving from the identification of inequalities towards successful interventions.

(b) Addressing gender complexities beyond ready-to-apply packages: Strategic gender research that engages with local knowledge could also help to overcome limitations of generalised 'gender packages' by contributing to tools and resources that reflect situated knowledge and are adapted to the concerns and particularities of local communities. GENNOVATE, for instance, has developed a series of evidence-based inputs and recommendations to ensure gender considerations are integrated into projects on various development, nutrition, climatesmart agriculture, conservation agriculture, mechanisation, or farmer training events. ${ }^{3}$ These resources and tools are designed to be adapted to different contexts, with some having broad geographical relevance and others only regional, country, or community-level significance. For instance, the resource 'Gender in Agricultural Mechanization' (Kawarazuka et al., 2018) presents case studies of gender implications in mechanisation in roots, tubers, and banana crops across geographies evidencing positive and negative outcomes which could help engineers and agronomists working with these crops to ensure mechanisation does not further local inequality.

(c) Relational approaches beyond women-only measures: The CGIAR often approaches gender mainstreaming through an exclusive focus on women-both internally (e.g. in their aim of ensuring representation of women across the organisational hierarchy) and externally (e.g. in their goal of empowering rural women 
to achieve CGIAR goals). However, most of the gender specialists interviewed emphasised the relational character of gender equality; with some of them recommending a family, household, or another integrative approach to advance gender equality in the geographies where the CGIAR works. Focus group discussions in rural communities also often emphasised relational dimensions of gender equality at the household and community levels. A relational gender mainstreaming strategy would help to ensure that both men and women have an equal opportunity to participate in and to overcome limitations of common practices where only men attend agricultural trainings and only women attend gender equality talks. As pointed out by an adult Ethiopian woman: 'I wish there were different programs that engaged our men on equality of men and women, to teach them to stop treating women as if they are their property.'

Our three suggestions show how a transdisciplinary perspective on situated knowledge can contribute to reflective approaches to gender in the CGIAR and beyond. The ongoing transformation of the CGIAR system reflects its embeddedness in wider shifts of the development sector-which aim to diversify its mission beyond economic growth and technological innovation via sustainable development goals (SDG) including gender equality (SDG 5). However, the power of the organisation lies in its agricultural research work rather than on its focus on gender transformation (CGIAR-IEA, 2017). This may result in a gender mainstreaming strategy with insufficient conceptual reflectivity or institutional depth. The acknowledgement of distinct forms of situated knowledge embedded in different sites of knowledge production could mitigate this risk. A transdisciplinary perspective, as the one advanced in this chapter, can therefore contribute to understanding heterogeneous (e.g. cultural, economic, environmental, religious) relations and negotiating their relevance for fostering gender equality in agricultural contexts.

\section{Notes}

1 See all centres and their locations: https://www.cgiar.org/research/research-centers/.

2 The current CGIAR Gender Strategies involve two approaches: strategic gender research to deepen understanding of how gender disparities or gender relations affect agricultural innovation, productivity, and sustainability; and gender integrated analysis into ongoing agri-food systems research: https://gender.cgiar.org/genderplat form/gender-strategies/.

3 All GENNOVATE resources are available at: https://gennovate.org/.

\section{References}

Anderson, E. (2000). Feminist epistemology and philosophy of science. Stanford Encyclopaedia of Philosophy.

Baden, S. and Goetz, A. M. (1998). Who needs [sex] when you can have [gender]. In: Jackson, C. and Pearson, R. (eds.). Feminist visions of development, London: Routledge, $19-38$. 
Badstue, L., Petesch, P., Feldman, S., Prain, G., Elias, M. and Kantor, P. (2018). Qualitative, comparative, and collaborative research at large scale: An introduction to GENNOVATE. Journal of Gender, Agriculture and Food Security, 3(1), 1-27.

Beck, E. (2017). What a feminist curiosity contributes to the study of development. Studies in Comparative International Development, 52(2), 139-154.

Cavaghan, R. (2017). Bridging rhetoric and practice: New perspectives on barriers to gendered change. Journal of Women, Politics \& Policy, 38(1), 42-63.

*CGIAR (2020a). Framework for gender, diversity and inclusion in CGIAR's workplaces. https://hdl.handle.net/10568/108036

^CGIAR (2020b). Action plan for gender, diversity and inclusion in CGIAR's workplaces: Principles, key Objectives, performance benchmarks and targets. https://hdl.handle .net/10568/108037

*CGIAR Consortium Board (2011). Consortium level gender strategy. https://cgspace.cgiar .org/bitstream/handle/10947/2630/Consortium_Gender_Strategy.pdf?sequence $=4$

*CGIAR Consortium Office (2016). CGIAR strategy and results framework 20162030. https://development.science.ku.dk/development-news/news/cgiar-strategy -and-results-framework/CGIAR_Strategy_and_Results_Framework.pdf

*CGIAR-IEA (2017). CGIAR-IEA. Evaluation of gender in CGIAR, Independent Evaluation Arrangement (IEA) of CGIAR.

^CGIAR System Council (2019). One CGIAR: A bold set of recommendations to the system council. CGIAR 9th meeting in Chengdu, China (13-14 November).

Cornwall, A., Harrison, E. and Whitehead, A. (2007). Gender myths and feminist fables: The struggle for interpretive power in gender and development. Development and Change, 38(1), 1-20.

Charlesworth, H. (2005). Not waving but drowning: Gender Mainstreaming and Human Rights in the United Nations. Harvard Human Rights Journal, 18, 1-18.

Haraway, D. (1988). Situated knowledges: The science question in feminism and the privilege of partial perspective. Feminist Studies, 14(3), 575-599.

Harding, S. (2015). Objectivity and diversity: Another logic of scientific research. Chicago: University of Chicago Press.

Hawthorne, S. (2004). The political uses of obscurantism: Gender mainstreaming and intersectionality. Development Bulletin, 64, 87-91.

Kawarazuka, N., Prain, G., Forsythe, L., Mayanja, S., Mudege, N. N., Babini, C. and Polar, V. (2018). Gender in agricultural mechanization: Key guiding questions. CIP.

Lacey, H. (2019). Ciência, valores, conhecimento tradicional/indígena e diálogo de saberes. Desenvolvimento e Meio Ambiente, 50, 93-115.

Longino, H. E. (2017). Feminist epistemology. In: Greco, J. and Sosa, E. (ed.). The Blackwell Guide to Epistemology, Oxford: Blackwell, 325-353.

Ludwig, D. and El-Hani, C. N. (2020). Philosophy of ethnobiology: Understanding knowledge integration and its limitations. Journal of Ethnobiology, 40(1), 3-20.

Lyons, T., Curnow, J. and Mather, G. (2004). Developing gender mainstreaming and "gender respect". Development Bulletin, 64, 37-41.

Palmary, I. and Nunez, L. (2009). The Orthodoxy of gender mainstreaming: Reflecting on gender mainstreaming as a strategy for accomplishing the Millennium Development Goals'. Journal of Health Management, 11(1), 65-78.

$\star$ Özgediz, S. (2012). The CGIAR at 40: Institutional evolution of the world's premier agricultural research network. https://cgspace.cgiar.org/handle/10947/2761

Østebø, M. T. (2015). Translations of gender equality among rural Arsi Oromo in Ethiopia. Development and Change, 46(3), 442-463. 
Tegbaru, A., Fitzsimons, J., Gurung, B. and Odame, H. H. (2010). Change in gender relations: Managerial and transformative approaches of gender mainstreaming in agriculture. Journal of Food, Agriculture and Environment, 8(3/4), 1025.

Razavi, S. and Miller, C. (1995). From WID to GAD: Conceptual shifts in the women and development discourse. Occasional Article 1, no. 3, UNRISD.

Sohal, R. (2005). Strategic engagements: Exploring instrumentalist approaches to engendering development. Canadian Journal of Development Studies, 26(1), 665-676.

Verma, R. (2014). Business as unusual: The potential for gender transformative change in development and mountain contexts. Mountain Research and Development, 34(3), 188-196. 